\title{
SECUENCIA DE FASES POSTFORMATIVAS EN IZAPA, CHIAPAS, MÉXICO *
}

\author{
por Thomas A. LEe, Jr. \\ New World Archaeological Foundation
}

Izapa, uno de los sitios precolombinos más grandes en el litoral del Pacífico, se localiza en el corazón de la rica zona del Soconusco en Chiapas, México, cerca de la actual frontera con Guatemala, (Lowe 1965; figura 1). El sitio mide unos $2 \mathrm{~km}$ de largo por $1 \mathrm{~km}$ de ancho y está situado como a $50 \mathrm{~km}$ del océano, en una planicie tropical que recibe anualmente unos 3 metros de precipitación pluvial. El gran número de monumentos de piedra tallada en Iżapa son pruebas de la opulencia que alcanzaron los ocupantes del sitio en algunas fases de su larga ocupación.

Fueron estos monumentos los que primeramente llamaron la atención de los arqueólogos por el sitio (Sterling 1943). Sin embargo, no fue sino hasta 1962, cuando la BYU-New World Archaeological Foundation formuló un amplio programa de investigaciones arqueológicas, de cuatro años de duración. Parte de este programa incluía levantamiento de planos y mapas, que sirvieron para localizar más de 162 estructuras las que quedaron incluidas en un mapa básico en escala de 1:1000, con curvas de nivel a intervalo de un metro. El tamaño varía desde pequeñas y sencillas estructuras domésticas, de un metro de altura, hasta verdaderos complejos de pirámides escalonadas de más de $20 \mathrm{~m}$ de altura. Todos los monumentos de piedra fueron localizados en el mapa básico y nos dan el siguiente número: 81 estelas, 70 altares, 3 tronos y 60 monumentos diversos. Un $50 \%$ de las estelas están esculpidas, pero de los altares solamente una tercera parte presenta escenas talladas.

Las excavaciones efectuadas durante las cuatro temporadas produjeron una considerable cantidad de artefactos, la mayoría de los cuales

- Trabajo presentado en la $35^{a}$ Asamblea Anual de The Society for American Archaeology, en el Museo Nacional de Antropología del INAH (1970), México.

Tradujo del inglés María Teresa Alvarado Z., bajo la supervisión de Carlos Navarrete. 
son tiestos, pero también fue rescatada una importante cantidad de vasijas completas dejadas como ofrendas.

En la parte norte del sitio - a la que en lo sucesivo nos referiremos como Grupo F-, se localizó una importnte secuencia estratigráfica de 45 ofrendas en el Montículo 125a. Éstas varían en tiempo desde unos 100 a.C. hasta alrededor de 1100 d.C. Las 265 vasijas completas o restaurables de estas ofrendas constituyen la base estratigráfica del estudio Posformativo de la cerámica de Izapa. Conjuntamente con vasijas del mismo periodo de tiempo de las demás partes del sitio, pero principalmente de otras estructuras en el Grupo F, hacen un total de más de 700 vasijas relacionadas con este estudio. No se han considerado los tiestos dentro del estudio de la cerámica, pero sí se usarán posteriormente para extender y ampliar los tipos y variedades ya establecidos.

El estudio de cerámica ha sido hecho bajo el sistema de mayor uso en la zona del Sur de Mesoamérica, el del Tipo-Variedad con sus categorías mayores de Grupo Cerámico y Cerámica (Ware) (Willey, Culbert and Adams 1967:303-5; Smith and Gifford 1965:501, footnote 3; Sabloff and Smith 1969).

Como el espacio aquí no permite una detallada descripción de la cerámica, como quisiera hacerla para cada fase, se mencionarán únicamente los rasgos más característicos. Se enfatizará la categoría de las vasijas por ser ésta la línea de evidencia más completa de que disponemos.

El título de este trabajo hace alusión a dos fases Posformativas que no están consideradas aquí (figura 1). El material de éstas: Guillen y Hato, Protoclásico temprano y tardío, respectivamente, está siendo estudiado por Gareth W. Lowe. Las fases Formativas o Preclásicas están bajo el análisis de Susanna Ekholm-Miller de las cuales ya ha publicado un informe sobre la más temprana (Ekholm 1969).

\section{IZAPA}

(FIGURA 2)

Son siete las ofrendas más tempranas en el Grupo $\mathrm{F}$, asignadas a la fase Izapa. Todas las ofrendas son votivas, con pocas vasijas, excepto una consistente en muchas vasijas, una urna grande, orejeras y cuentas de jade, así como fragmentos de navajas de obsidiana.

Las formas más características de la fase Izapa son platos chicos de fondo plano y bordes vueltos hacia afuera, cajetes trípodes de 
soportes cónicos, cilindros altos y jarros con hombros planos y bordes vueltos hacia afuera. De esta misma fase son conocidos una efigie trípode y un pedestal de olla. La superficie tiene engobe de color café rojizo. La decoración es limitada y consiste en muescas en la orilla de los hombros de los jarros, así como diseños de múltiples líneas incisas rectas y curvilíneas con formas zoomorfas sencillas. El modelado se limita a dos vasijas de efigie con poco relieve.

\section{JARITAS \\ (Figura 3)}

Se han asignado definitivamente ventiún ofrendas a la fase Jaritas. Cinco de estos ejemplos eran grandes urnas y sus accesorios mortuorios asociados, que siempre constaron de gran cantidad de alfarería, collares y brazaletes de jade y hojas de obsidiana. El resto eran ofrendas votativas con dos o tres vasijas cada una.

Durante la fase Jaritas, el tamaño de las vasijas iba siempre en aumento. Independientemente de todo, la forma más característica eran los cajetes grandes de fondo plano, soportes trípodes más bien cortos y sólidos, paredes extendidas y rebordes labiales. Son muy comunes los jarros con fondos cóncavos, cuerpo redondo y cuellos estrechos con bordes hacia afuera (figura $12, b$ ); es también frecuente encontrar en esta forma un borde angosto. Durante esta fase es notable la presencia de vasos de cintura estrecha y soportes cónicos huecos. De menor importancia son los vasos altos y los platos. De esta misma fase es conocida una sola vasija mamiforme.

Mientras que la mayor parte de vasijas se elaboran en barro café con engobe café rojizo, se encuentra alfarería negra pulida que está definitivamente relacionada con la negra de borde blanco, tradicional en el centro de Chiapas. La decoración modelada en la cerámica de esta fase se limita a apéndices en los bordes, dispuestos por pares y algunas veces recortados y perforados; también se encontró una vasija con imagen. Triángulos toscamente recortados y múltiples líneas inclinadas son también comunes. Con frecuencia los fondos de los tazones y jarros tienen grabadas figuras estilizadas, humanas y animales, dentro de un estilo esquemático a base de múltiples líneas paralelas. 


\section{KATO}

(FIGURA 4)

Durante la fase Kató, cuando menos trece unidades de material cultural fueron enterradas en el Grupo F. De estas trece, ocho eran ofrendas votivas y cinco correspondían a entierros. Cuatro de estos entierros eran grandes urnas asociadas con otras treinta vasijas. Las ofrendas votivas contenían pocas vasijas y rara vez alguna otra cosa más. Por otro lado, las urnas contenían casi siempre artefactos de otro material como: obsidiana en forma de núcleos, navajas y puntas de lanza pulidas y solamente un objeto de jade. Pequeñas cantidades de malaquita, galena y mica biotita, se encuentran en asociación con otras urnas. También se incluyen partes de pizarra, cristal de cuarzo y una piedra con agarradera, similar a las usadas por los jugadores de pelota.

Los tazones con cuellos altos y base de pedestal o bien de soportes trípodes triangulares, cortos y huecos, horadados por los dos lados, constituyen la clave de esta fase. Son también muy comunes los cajetes de fondo plano, paredes de bordes hacia afuera, con soportes huecos, trípodes, y mamiformes pequeños, con una hendidura; también aparecen los cajetes de fondo plano, sin soportes.

La decoración modelada se enfatiza mucho durante esta fase y se presenta en forma de cejas paralelas que circundan la boca de las vasijas, protuberancias o relieves bajos simétricamente esparcidos sobre el cuerpo de la vasija, así como figuras de animales estilizadas en bajo relieve. Se hicieron incisiones toscas en el exterior, circundando las vasijas $\mathrm{y}$ algunas veces delineadas con pintura negra. La técnica de incisión acanalada es importante y se hace en forma de múltiples líneas rectas, paralelas y cortas, en el cuerpo y la boca de las vasijas.

R. E. Smith (comunicación personal), ha identificado cuatro vasijas mayas policromadas, dos de base anular y dos cajetes trípodes, y las ha colocado en el tipo Dos Arroyos Orange Polychrome, que viene a corresponder con Tzakol II-III, en fecha equivalente a la fase Katb.

\section{LOROS}

(Figuras 5, 6)

Durante la fase Loros, el modelo de ofrenda cambia ligeramente, del establecido antes. Las ofrendas votivas son las más comunes todavía, y los entierros en urna (figura $12, d$ ) son la moda mortuoria. 
La presencia de tres tumbas de mampostería con sus respectivos accesorios mortuorios suman un nuevo elemento al patrón de ofrendas.

Entre otros artefactos se encuentran: una especie de anillo de ámbar y una figurilla de barro en forma de sacerdote en posición sedente; hay también navajas de obsidiana, ocarinas con efigies de pájaro, cinceles de jade, un vaso de ónix con pedestal, orejeras de barro, pedacitos rectangulares de hematita, cuentas tubulares de coral, y pequeñas cuentas discoidales de obsidiana, todo esto para enumerar algunos de los artefactos encontrados.

La forma más sobresaliente de vasijas de la fase Loros es la cilíndrica, trípode, de soportes que recuerdan los típicos de Teotihuacán. Estos cajetes cilíndricos tienen los soportes sólidos o huecos; algunos tienen también tapadera. Muy importante en esta fase son los cajetes de paredes cortas y verticales, de fondo recto, con soportes trípodes, cónicos, agudos y sólidos; hay jarros completamente esféricos, sin cuello, con bordes rectos volteados hacia afuera, que son comunes en esta fase. Aparecen frecuentemente las vasijas efigie.

La técnica de decoración cambia notablemente durante esta fase. La incisión, que en otro tiempo era tan importante, aquí es tara. La pintura es la forma de decoración más común, aunque la variedad es limitada. En las técnicas positiva y negativa, se encuentra una pintura delgada de color negro sobre una base de hematita. Algunas veces el engobe es dejado a la vista para crear una decoración trícroma; en cuando menos un ejemplo se encuentra el negro sobre base blanca. El blanco se usa a veces para rellenar incisiones decorativas. Es también frecuente encontrar decoración en forma de agujeros en la parte frontal de soportes trípodes huecos almenados.

METAPA

(Figura 7)

Como en la fase anterior, la ofrenda votiva es el tipo más importante de ofrenda. Aún ocurren los entierros en urnas pero con mucha menor frecuencia, y solamente una tumba hecha de piedras alineadas ha sido asignada a esta fase. El contenido de todas las ofrendas se limita a vasijas de barro, contrariamente a las fases anteriores en que siempre se encontraban otros artefactos de diferente material. Entre las formas de vasijas más comunes se cuentan los tazones hemisféricos, tazones poco profundos con base de pedestal, jarros de cuerpos cortos y redondos con cuellos rectos angostos (botellones), además 
de tazones trípodes de soportes huecos almenados, paredes bajas divergentes y bordes vueltos hacia afuera. Dentro de las urnas mortuorias se encontraron tazones grandes, redondos, con anchos bordes volteados hacia afuera.

La decoración consiste en líneas incisas con motivos decorativos simétricos y asimétricos aislados. El modelado es en forma de un acanalado horizontal y vertical, así como hoyuelos. La decoración grabada se limita a la parte anterior de los soportes huecos, representando caras humanas o diseños sencillos de ondulaciones o cordoncillo. La pintura es en negro delgado sobre una base de rojo hematita. Muchas veces la técnica es negativa. El relieve se encuentra en algunas vasijas y en diseños aislados.

Todas las vasijas, excepto las de soportes almenados, están hechas de diferente barro fino, aunque similar. La tradición de esta pasta fina se originó a finales de la fase Loros y su representante en nuestra fase es el Grupo Cerámico Tiquisate y otros grupos estrechamente relacionados. Éstos tienen un engobe o baño de color café o naranja y contrastan considerablemente con los tipos de pasta burda, al que corresponden ćàsi todos los tazones trípodes de soportes almenados.

\section{PEISTAL}

(FIgURA 8)

Las ofrendas más frecuentes en la fase Peistal son de tipo votivo, pero de las nueve encontradas ninguna contenía más de cinco vasijas y la mayoría solamente dos. Otros artefactos de alfarería asociados, están constituidos por un fragmento de flauta y un malacate, mientras que los artefactos de piedra consisten en un cincel de jade, una gran cuenta sencilla y un cristal chico de cuarzo.

Una ofrenda contenía una hoja de obsidiana de doble filo, de más de $50 \mathrm{~cm}$ de largo, enterrada en tal posición que las orillas de la hoja quedaban perfectamente alineadas con el eje norte-sur de la acrópolis del Montículo 125. Alrededor de la hoja estaban colocadas, hacia los puntos cardinales, cuatro vasijas, una de las cuales es una efigie correspondiente a un tipo del Grupo Cerámico San Juan, de la Cerámica Plumbate.

Las urnas y tumbas están aún presentes pero solamente se encontraron dos de cada una. Una de las últimas fue construida durante la fase Loros y reutilizada en la fase Peistal, en que se colocó una ofrenda votiva. La otra tumba contenía vasijas, un metate con efigie, 
un pedazo del reverso de un espejo, y fragmentos de navajas de obsidiana.

Una de las urnas contenía cuatro vasijas, una punta de lanza con forma de hoja de laurel, de calcedonia; dos discos de piedra arenosa con un mosaico de jade y un bellísimo pendiente ovoidal, de oro, decorado con dos cabezas de serpiente emplumada.

Durante esta fase aparecieron cinco basureros que contuvieron una o dos vasijas reconstruibles, muchos tiestos, y artefactos de otro material, como piedras en forma de navajas de obsidiana, machacadores, fragmentos de hacha y manos de metate. Los basureros están siempre asociados con montículos bajos y rectangulares, que hemos identificado provisionalmente como estructuras domésticas.

La cerámica dominante en esta fase corresponde al Grupo Cerámico San Juan y Cerámica Plumbate, que equivale a un desarrollo directo del tradicional de pasta fina, representado en la fase anterior por el Grupo Cerámico Tiquisate.

Las formas dominantes son cajetes profundos y algunos de forma compleja, todas con base sencilla y bordes planos gruesos, jarros de boca ancha con cuellos largos, rectos, con declive hacia adentro; también hay pequeños jarros de bordes rectos o vueltos hacia afuera; vasijas simples con efigies humanas y zoomorfas, estas últimas raras; y comales con y sin asa. Un incensario diferente a los encontrados, tiene la plataforma para quemar sostenida por figuras humanas y de animales, dispuestas a manera de soportes; aparecen en número de tres y hay figuras humanas con máscara de animal. Hay también incensarios tipo sahumador, que es la forma más común en esta fase. Para el desarrollo de incensarios en Izapa hay que ver el artículo de Lowe (1965).

La decoración de vasijas no utilizadas para quemar incienso es muy limitada en esta fase. Se encontró estuco verde claro sobre rosa, en una vasija y pudo haber sido aún más pintada, pero no hay ninguna evidencia. La decoración existente se limita a incisiones de líneas delgadas o anchas. La incisión ancha, de tres líneas paralelas, se encuentra en unidades aisladas, o como una línea que circunda la vasija ligeramente abajo del borde. Este tipo de decoración se presenta en una variedad tardía en la fase Peistal.

Las vasijas con efigies son sencillas y carentes de los detalles de las vasijas del Grupo Cerámico Tobil correpondiente a este momento. Las hay de dos tipos: humanas y animales, aplicadas en un lado de las vasijas. 
La efigie consiste en la cara del animal con apéndices resaltados en el cuerpo de la vasija, para representar otras partes de la especie modelada: patas, cola, manos, etcétera, completándose con líneas incisas.

No está dentro de los límites del presente trabajo la discusión de los problemas del origen y desarrollo de la Cerámica Plumbate, pero podemos apuntar la posibilidad de un desarrollo estratigráfico, estilístico y técnico, desde la Cerámica Tiquisate a la Cerámica Plumbate vía el Grupo Cerámico San Juan. De ahí que el Grupo Cerámico Tobil sea el producto final de una larga y gradual evolución.

\section{REMANSO \\ (Figuras 9, 10, 11)}

Cuando menos 19 ofrendas y 10 basureros han sido identificados como pertenecientes a la fase Remanso. El tipo de ofrenda más importante es del tipo votivo, del cual se localizaron 16. La mayor parte de estas ofrendas contenían de 2 a 3 vasijas cada una, aunque hubo un caso con 9. Entre los artefactos encontrados en estas ofrendas hay puntas de lanza, de pedernal y obsidiana, con forma de hoja de laurel; pequeños núcleos poliedros de obsidiana y cinceles de jade.

Se encontraron dos urnas, pero solo una contenía varias vasijas, así como dos discos y cuentas de jade.

Los diez basureros contenían, aparte de vasijas rotas: hachas, pedazos de piedra, silbatos, manos de metate y fragmentos de los mismos y un arete en espiral de barro, esto es para nombrar algunos de los artefactos asociados más comunes.

Las formas de vasijas típicas en la fase Remanso, son las que se encuentran asociadas al Grupo Cerámico Tobil y muy comunes en el Anaranjado fino. Los floreros en forma de barril y los jarros de fondo plano y cuellos rectos, se colocan en el primer lugar de las formas importantes.

Otras formas importantes son: jarros redondos trípodes con hendiduras laterales, tazones de paredes bajas, y las llamadas lámparas de chimenea; de éstas las hay de pedestal. Otras formas sobresalientes son tazones hemisféricos chicos, sahumadores y jarros pequeños de cuello vertical. Las urnas grandes son de dos formas, una semiesférica (figura 12, a) y otra semi-esférica con paredes superiores rectas (figura 12,c), ambas con bordes planos salientes. 
La decoración en las vasijas del Grupo Cerámico Tobil, consiste en modelado e incisión con la efigie de Tlaloc; entre los animales hay perros, venados, guajolotes y animales desconocidos.

En el modelado se pueden encontrar diseños grabados, que se presentan en bandas que semejan escritura o diseño cursivo; también líneas dispuestas en bandas paralelas, verticales, horizontales, y oblicuas.

Un buen ejemplo es una vasija que tiene tres monstruos de nariz ganchuda, grabados en el exterior y separados por tres líneas achaflanadas.

La técnica de impresión sellada, con diseños curvilíneos, es muy peculiar y se encuentra en la parte superior de dos jarros.

Algunas vasijas burdas o de fina textura, no plomizas, se encontraron en la ofrenda junto con vasijas del Grupo Cerámico Tobil. Hay jarros pequeños de cuellos verticales y bordes vueltos hacia afue$\mathrm{ra}$, cilindros altos, simples o complejos, con pintura aplicada, y jarros grandes de cuello vertical.

Diez muestras de carbón asociadas con los materiales Posformativos, fueron fechados por el método de radiocarbón. De las diez muestras fechadas solamente siete fueron aceptables en cuanto a la tipología de material asociado y fechas más o menos establecidas para ello en otros lugares (figura 1). El márgen de error de un sigma más o menos está indicado por las líneas arriba y abajo de cada fecha.

Desafortunadamente en las tres fases, Kató, Loros y Metapa, no se encontraron muestras adecuadas para el fechamiento de radiocarbón.

La fecha más tardía del Grupo $\mathrm{F}$ proviene de la Estructura 130, en asociación con material del Grupo Cerámico Tobil y data del comienzo de la fase Remanso. Se ha hecho comenzar esta fase en 900 por conveniencia.

En la figura 13 se puede ver el esquema del Montículo $125^{a}$, que da la idea de la compleja composición de los primeros dos o tres metros estratigráficos. Prácticamente todas las ofrendas amontonadas, cerca de la parte superior de la excavación central, son intrusivas en la última unidad de construcción de la fase Kató; esto indica que por más de 500 años se fueron colocando ofrendas en la misma unidad arquitectónica. El Montículo 125ạ, es típico de Izapa durante el Clásico tardío y el Posclásico temprano, en que la construcción fue mucho menor en comparación a las fases más tempranas. Sin embargo, la secuencia de ofrendas y el desarrollo arquitectónico nos muestran claramente una continua ocupación, desde más o menos el comienzo de la era cristiana hasta el Posclásico temprano. 


\section{BIBLIOGRAFIA}

EKHOLM, SUSANNA

1969 "Mound 30a and the Early Preclassic Ceramic Sequence of Izapa, Chiapas, México", Papers of the New World Archaeological Foundation, núm. 25. Provo.

LOWE, GARETH W.

1965 "Desarrollo y Función del Incensario en Izapa", Estudios de Cultura Maya, vol. V, pp. 53-63. México.

SABLOFF, JEREMY A. y ROBERT E. SMITH

1969 "The Importance of Both Analytic and Taxonomic Classification in the Type-Variety System", American Antiquity, vol. 34, núm. 3, pp. 278-285. Salt Lake City.

SMITH, Robert E. y J. C. GIFFord

1965 "Pottery of the Maya Lowlands", in Handbook of Middle American Indians, edited by Wauchope and Willey; vol. 2, Art. 19, pp.. 498-534. University of Texas Press. Austin.

STIRLING, MATTHEW W.

1943 "Stone Monuments of Southern Mexico", Bureau of American Ethnology, Bulletin 138. Washington.

Willey, Gordon R., T. PATRICK CUlbert y RICHARD E. W. ADAMS

1967 "Maya Lowland Ceramics: A Report From the 1965 Guatemala City Conference", American Antiquity, vol. 32, núm. 3, pp. 289-315. Salt Lake City. 


\section{ILUSTRACIONES}




\section{CRONOLOGIA POST-FORMATIVA DE IZAPA}

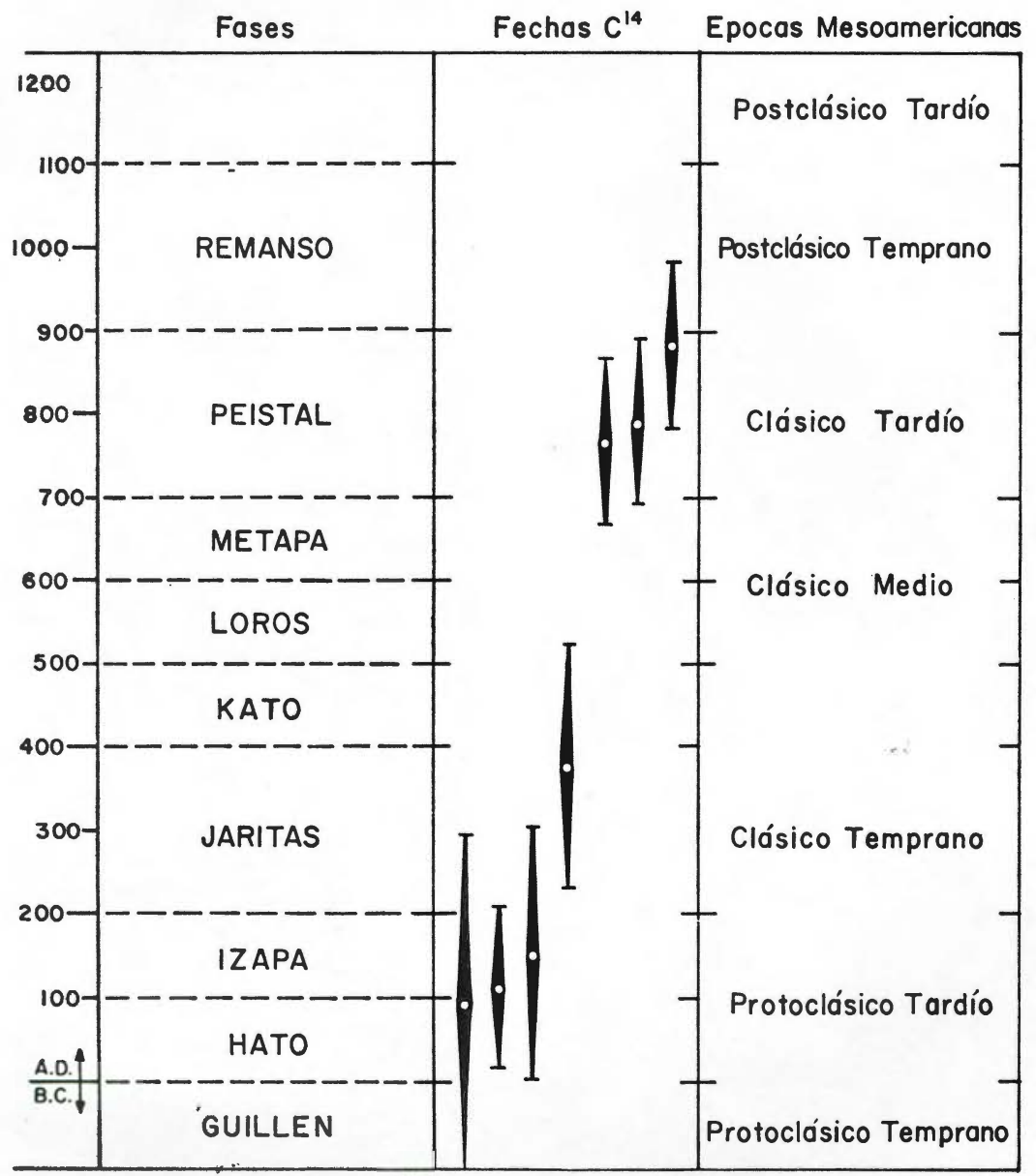

Figura 1. Secuencia de fases en Izapa con fechas de Radiocarbón y Épocas de Mesoamérica. 

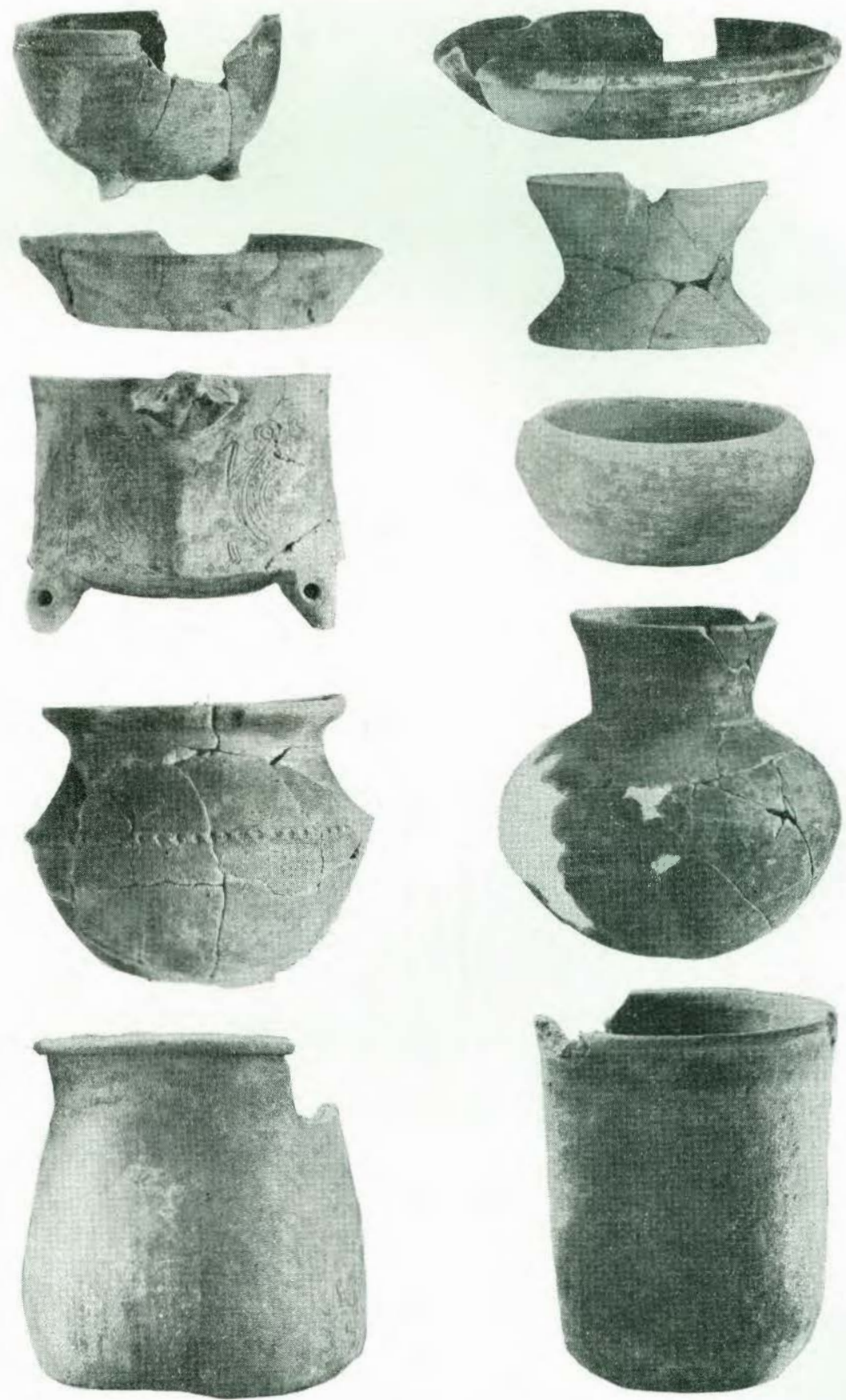

FIgurA 2. Vasijas de cerámica de la fase Izapa. Escala $1 / 4$ 

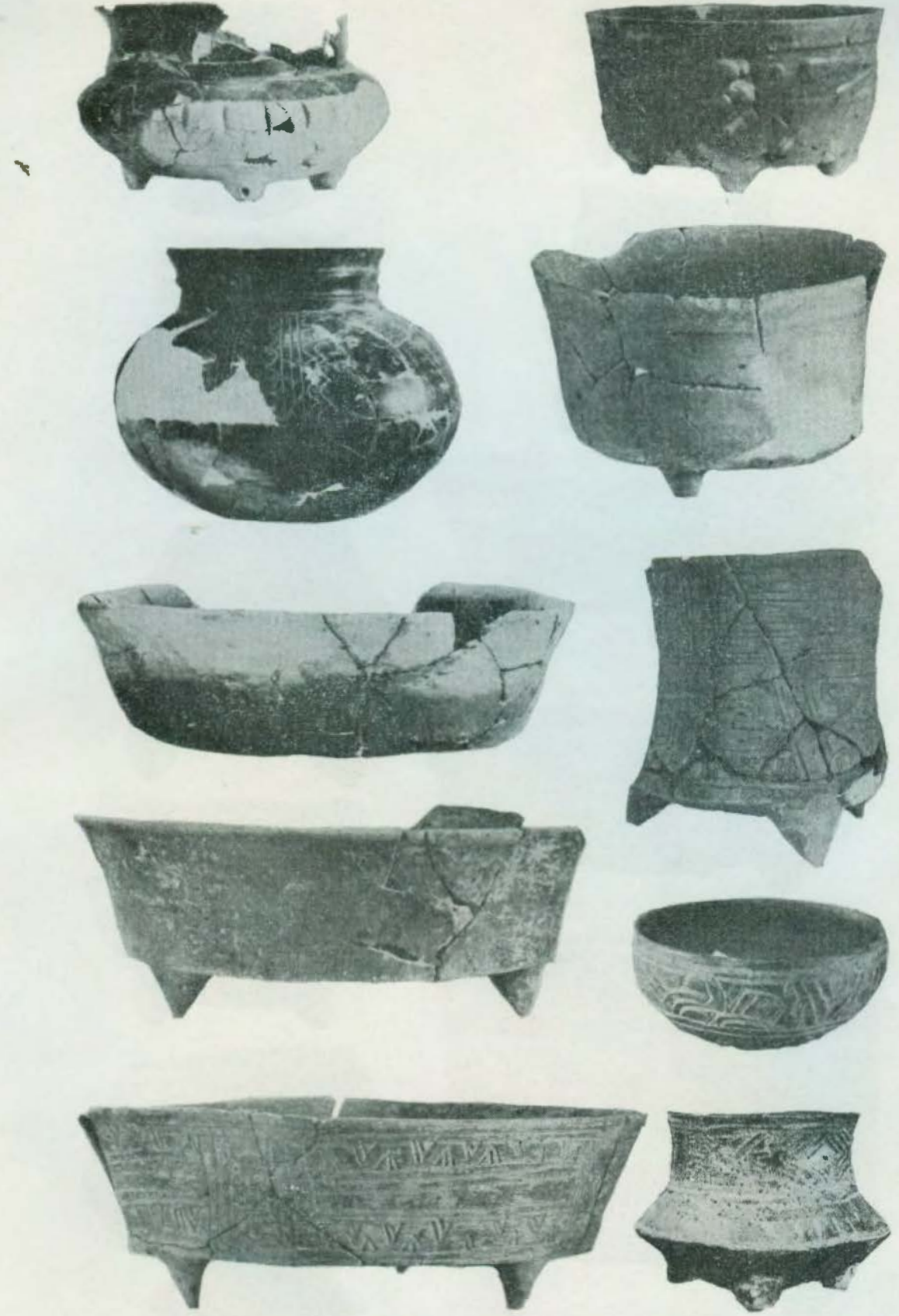

PIGURA 3. Vasijas de cerámica de $I_{2}$ fase Jaritas. Escala $1 / 4$

Estudios de Cultura Maya. Vol. IX, 1973

Instituto de Investigaciones Filológicas/

Facultad de Filosofía y Letras, UNAM 

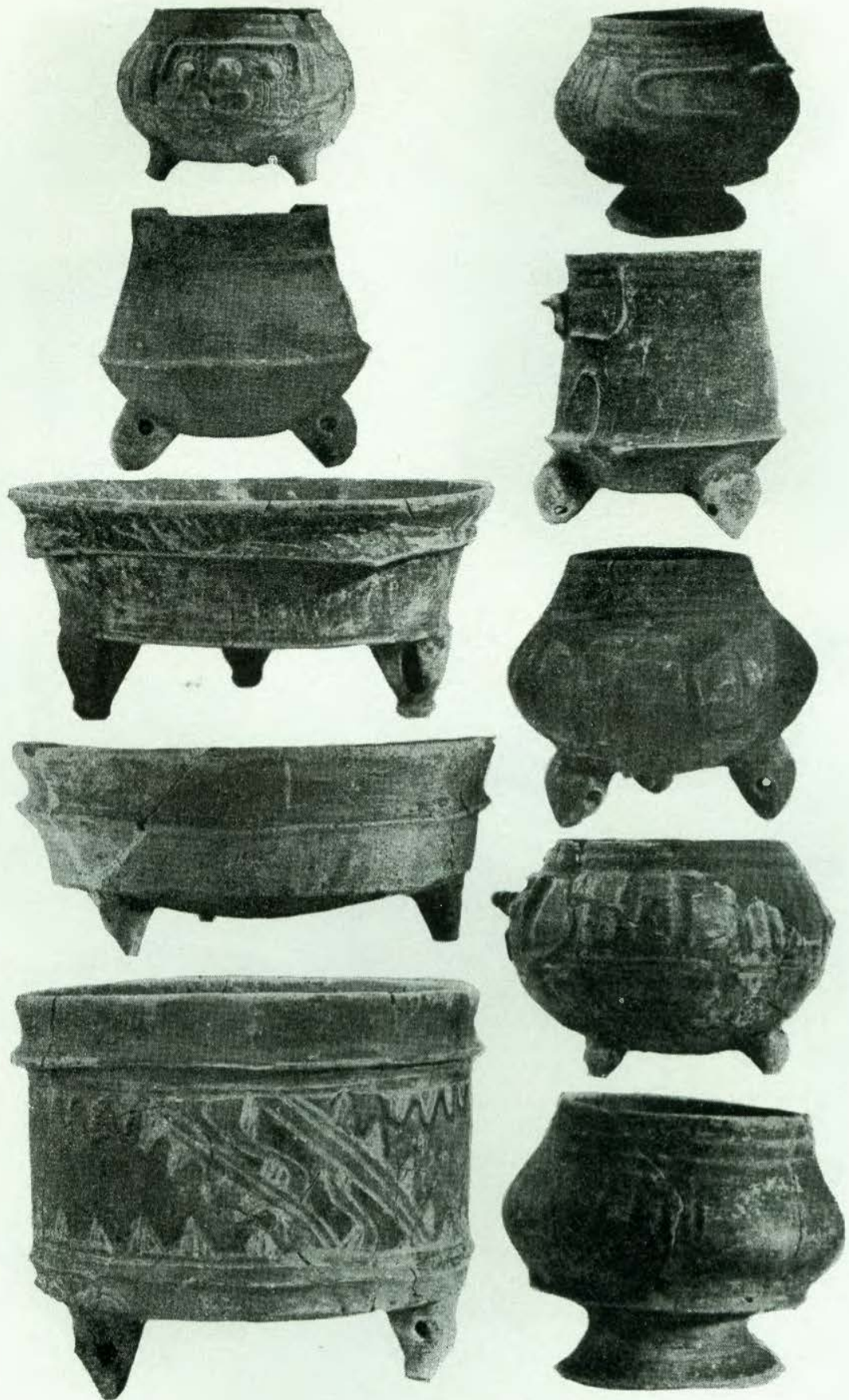

FIGURA 4. Vasijas de cerámica de la fase Kató. Escala $1 / 4$ 

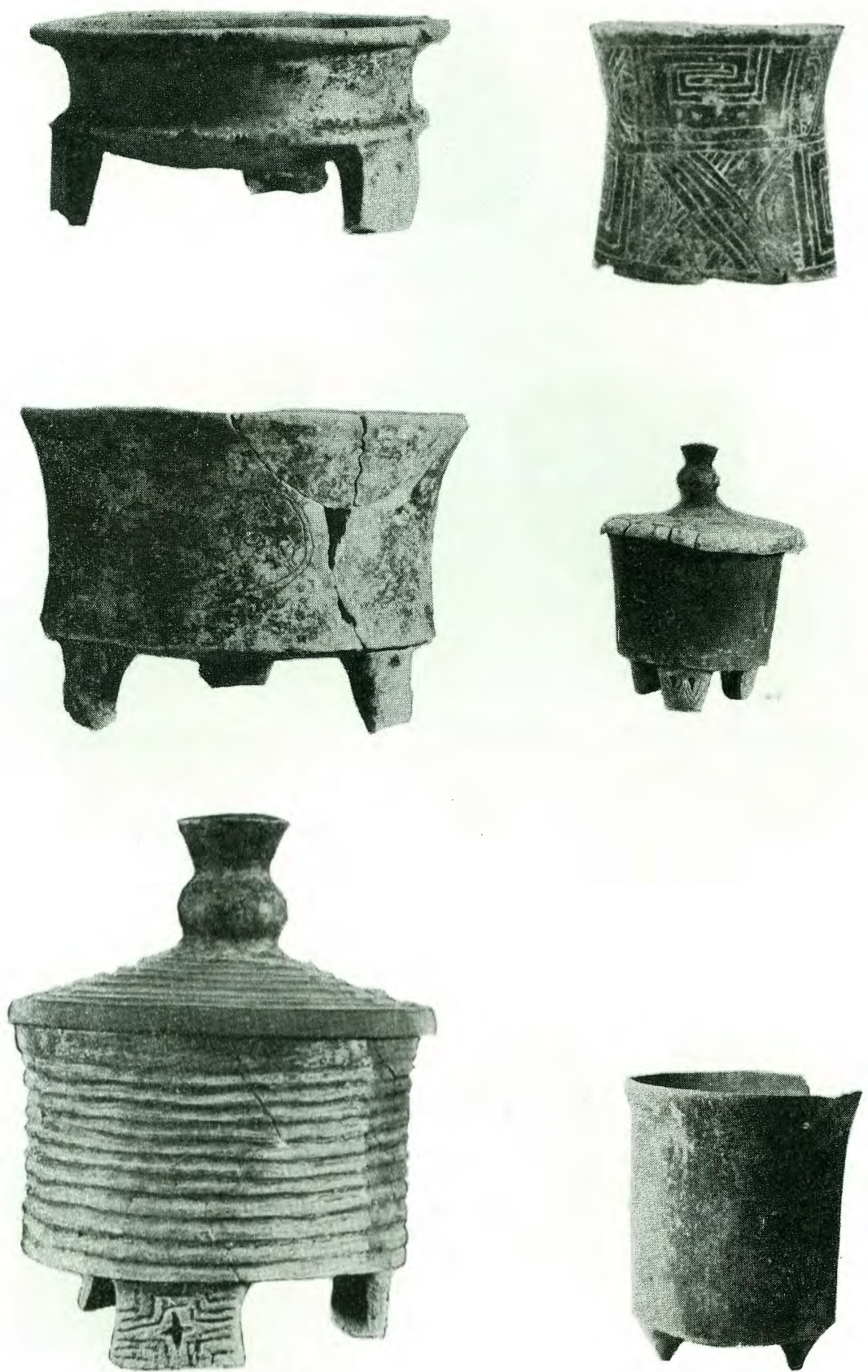

FiguRA 5. Vasijas de cerámica de la fase Loros. Escala $1 / 4$ 

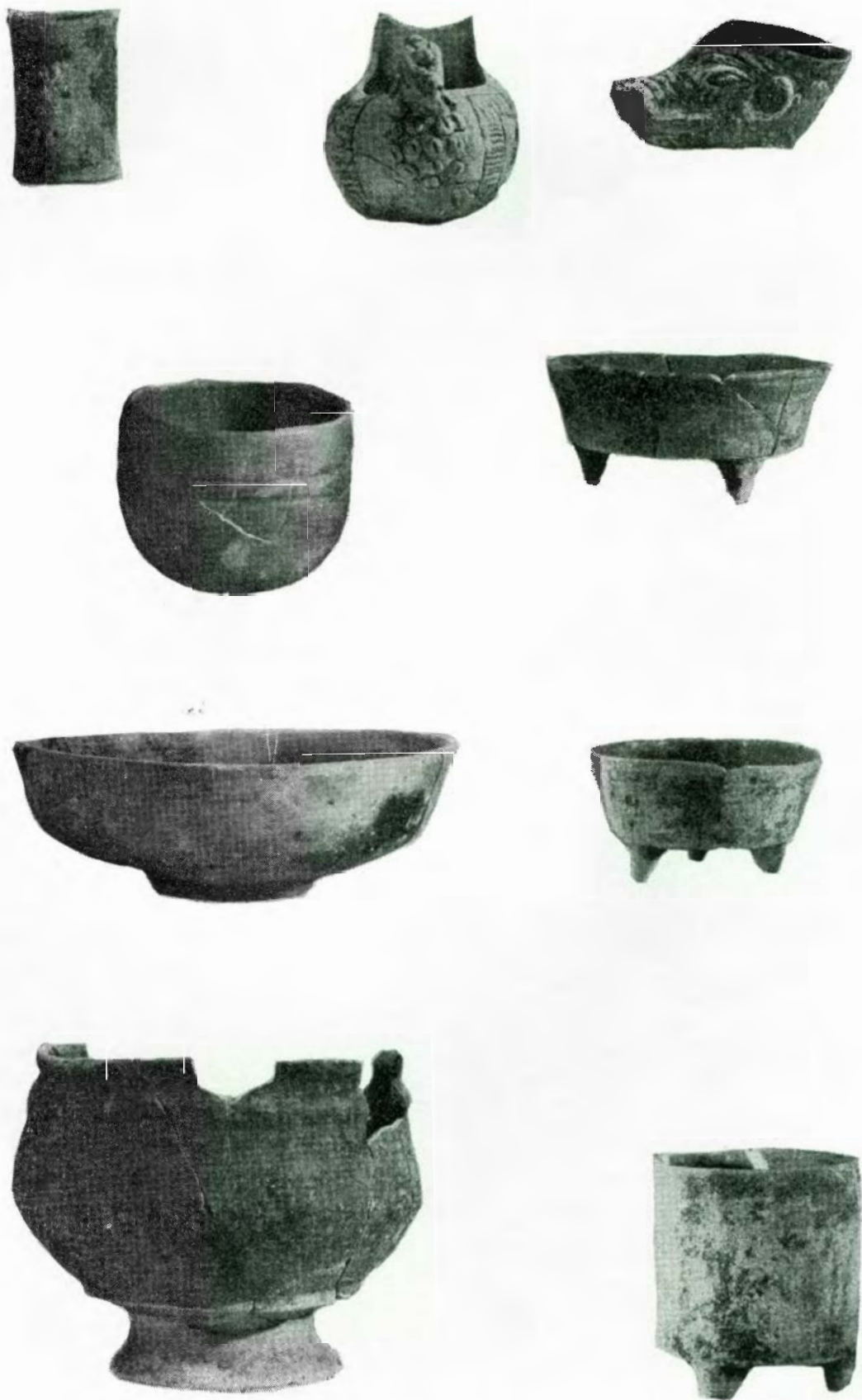

FigurA 6. Vasijas de cerámica de la fase Loros. Escala $1 / 4$ 

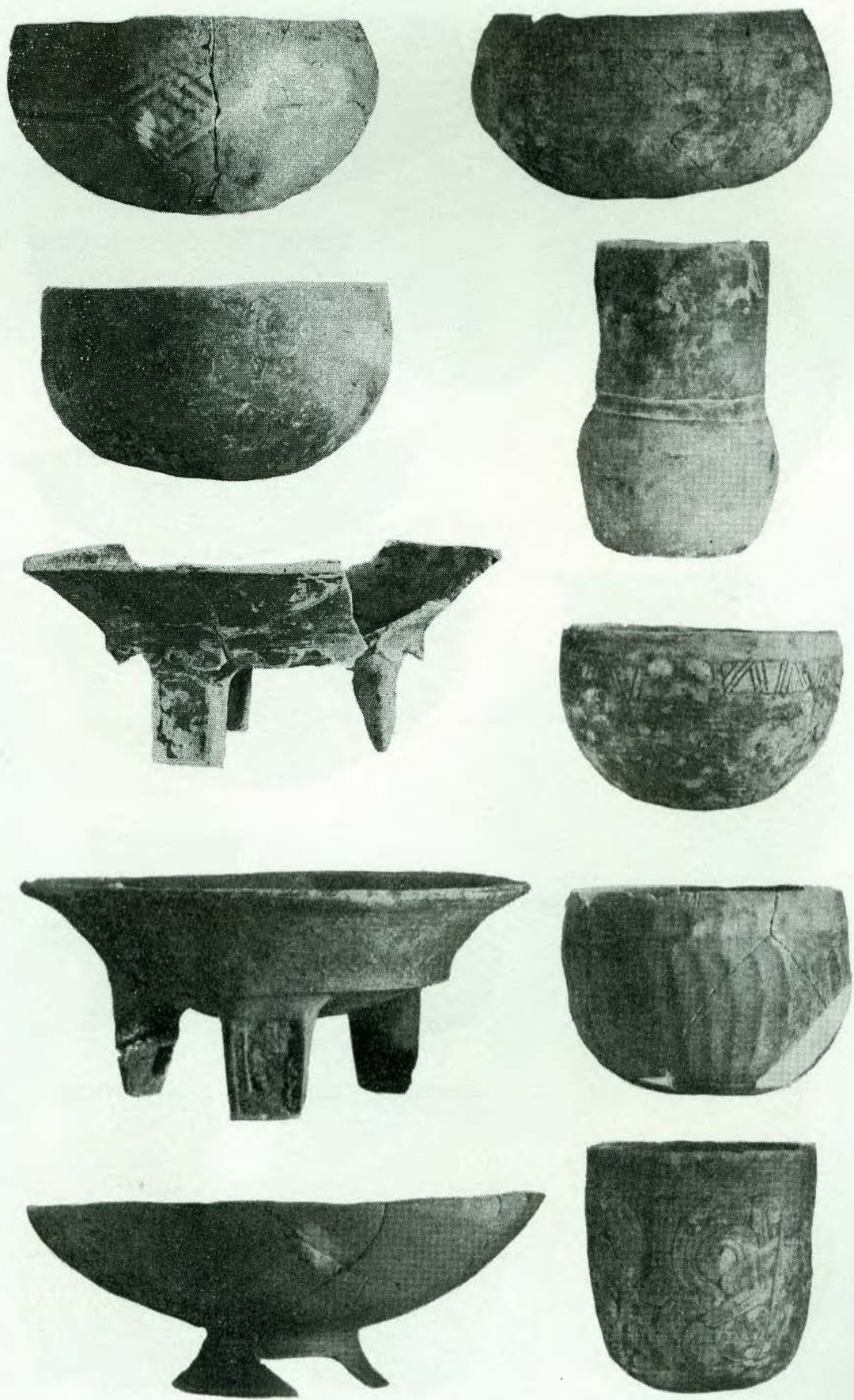

Figura 7. Vasijas de cerámica de la fase Metapa. Escala $1 / 4$ 

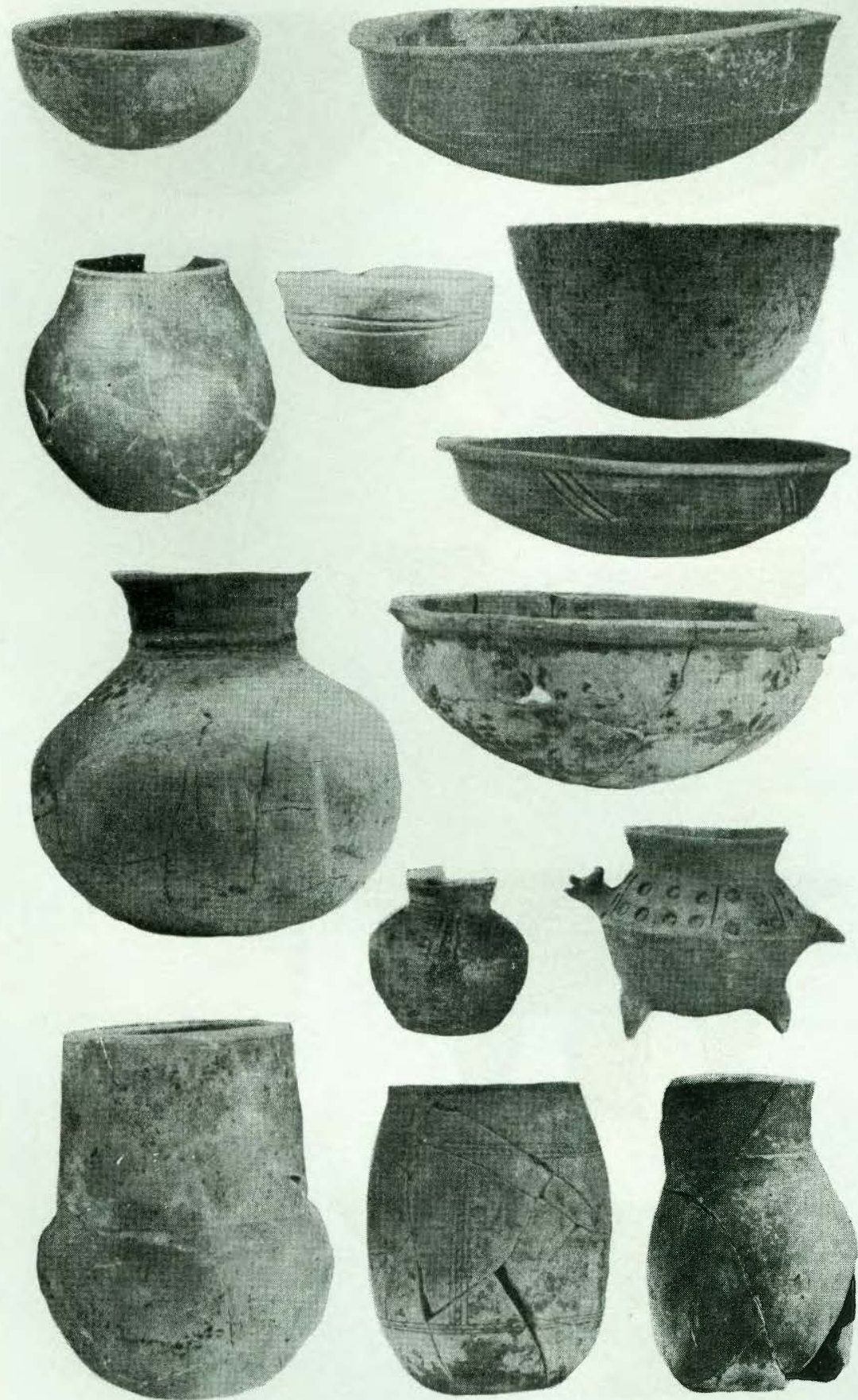

Figura 8. Vasijas de cerámica de la fase Peistal. Escala $1 / 4$ 

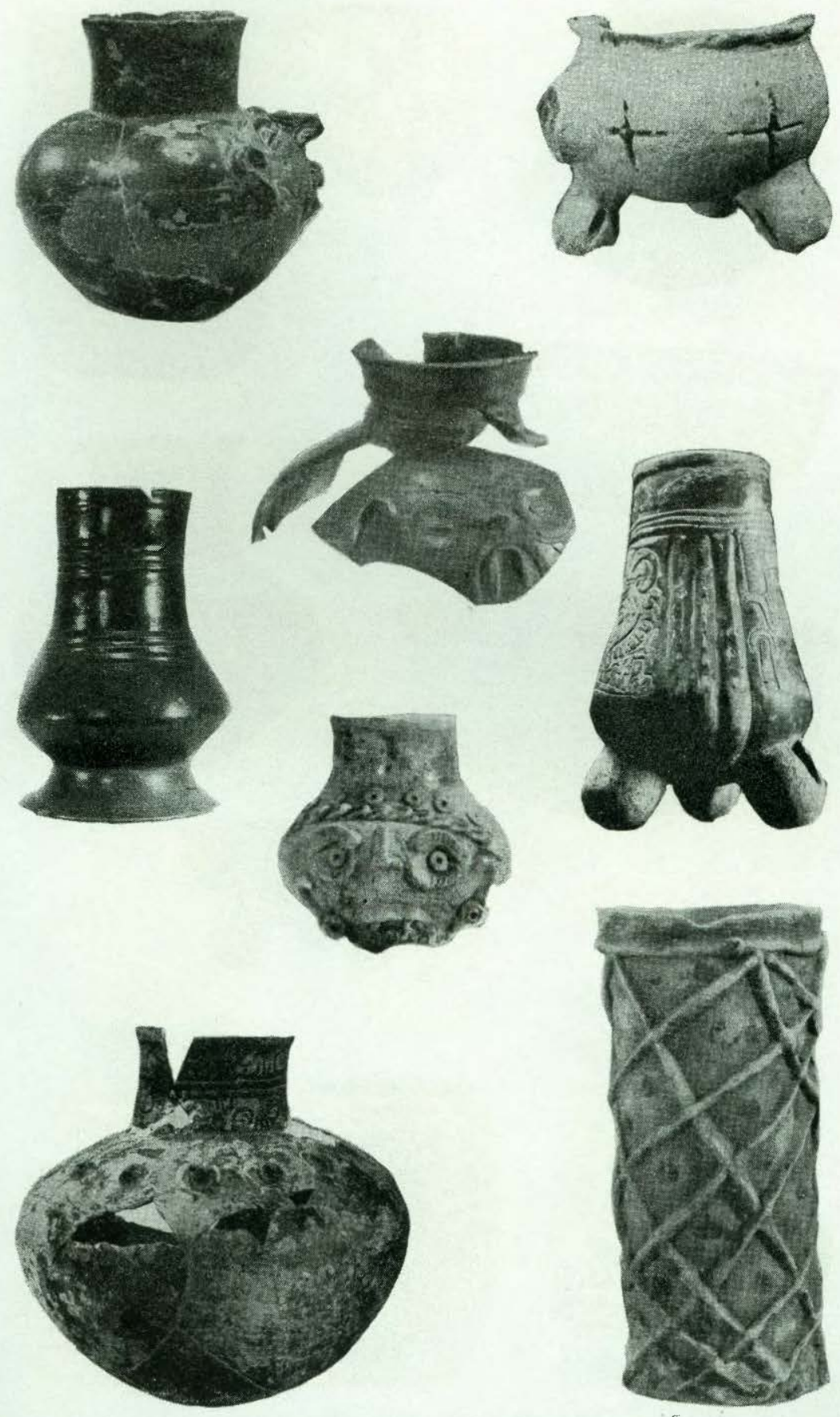

FIGURA 9. Vasijas de cerámica de la fase Remanso. Escala $1 / 4$ 

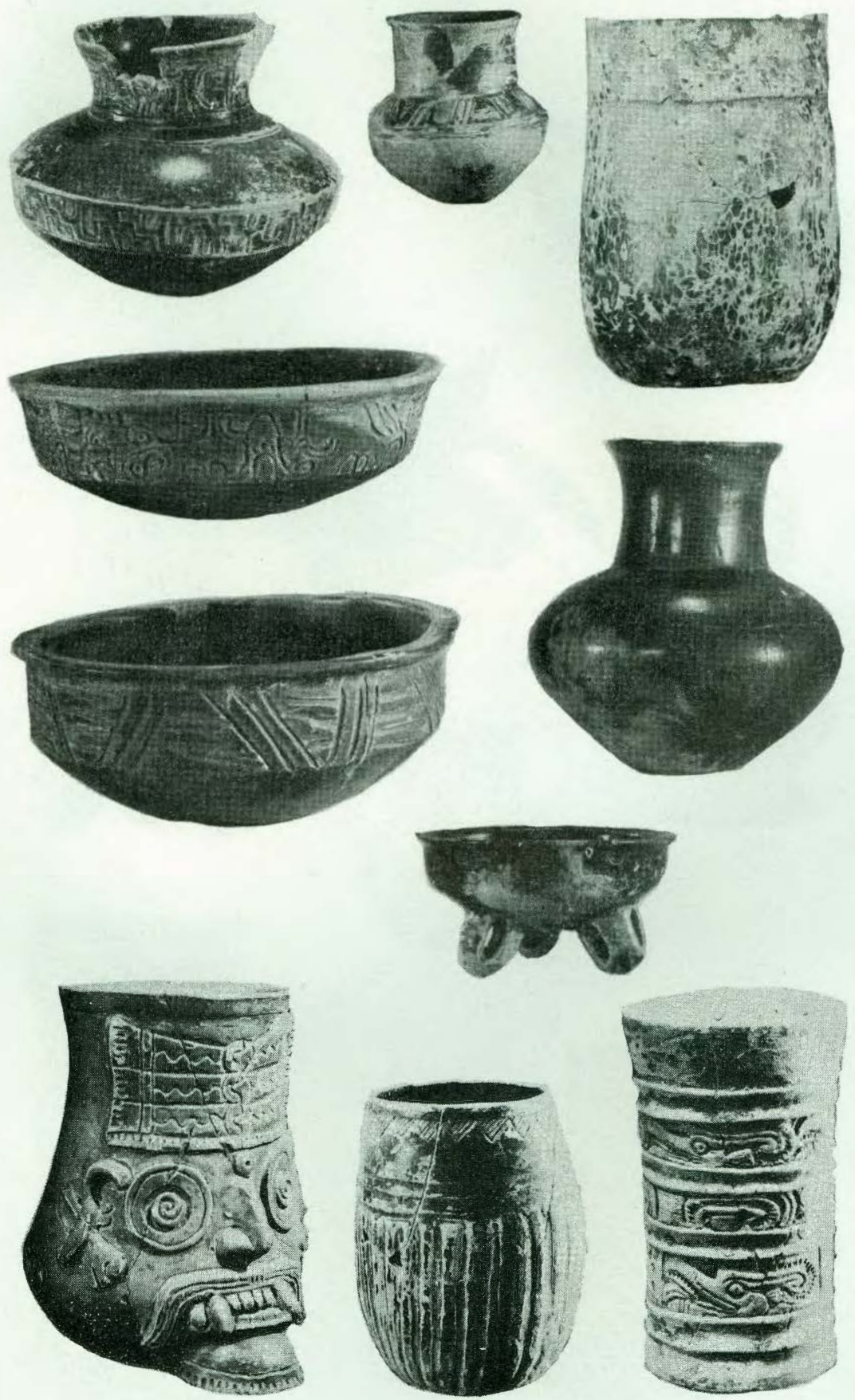

FIGURA 10. Vasijas de cerámica de la fase Remanso. Escala 1/4 

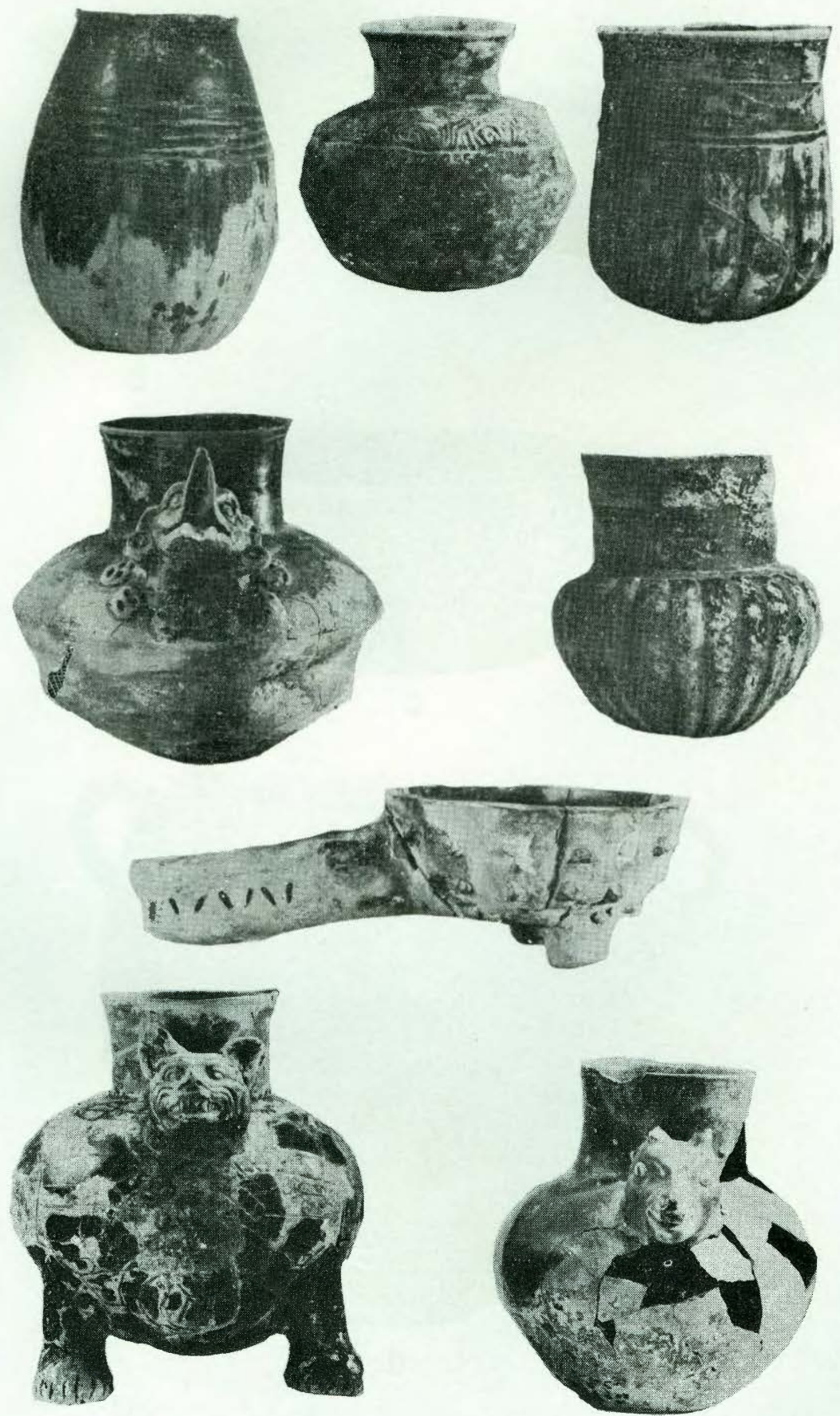

FIGURA 11. Vasijas de cerámica de la fase Remanso. Escala 1/4 

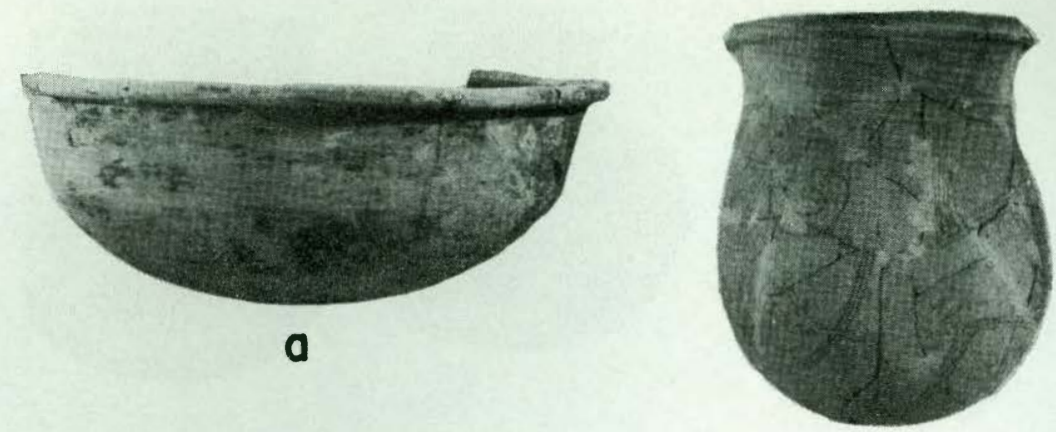

b
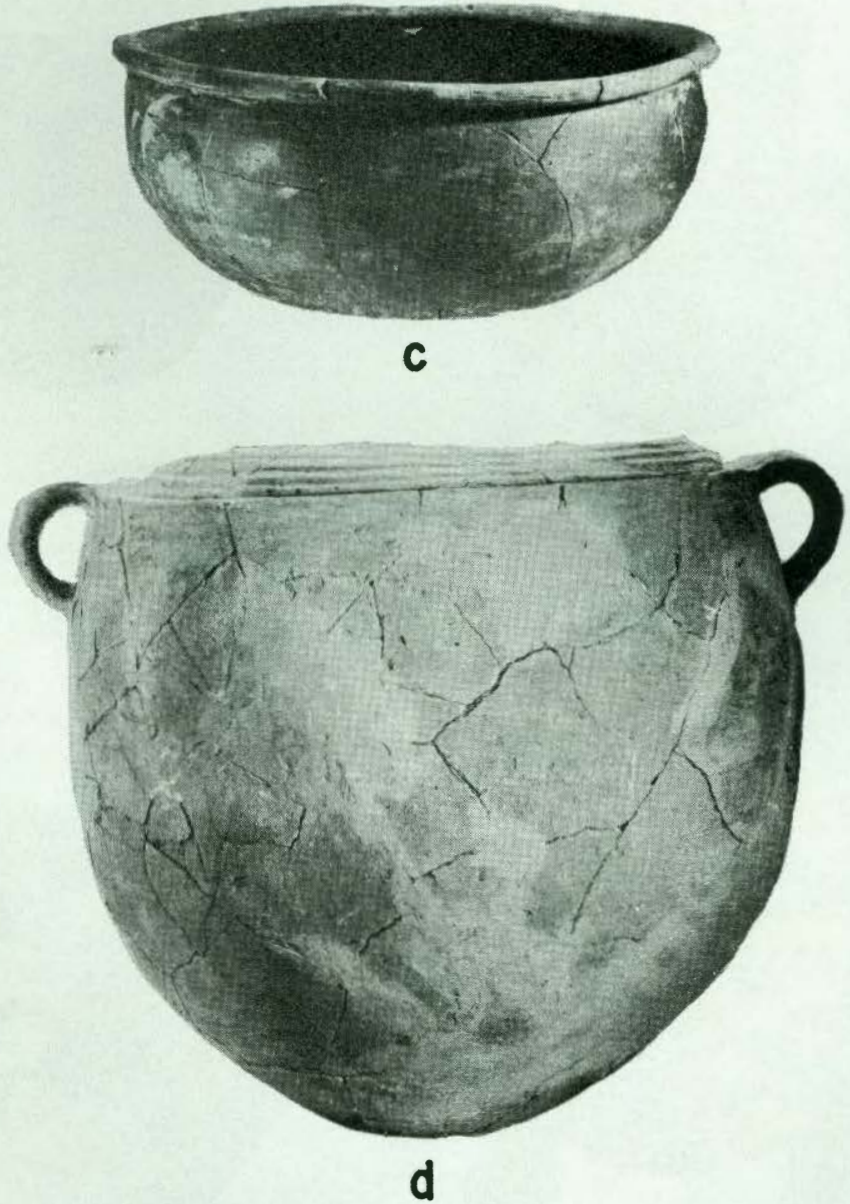

FIGURA 12. Vasijas de cerámica de varias fases. $a, c$, Remanso; $b$, Jaritas; $d$, Loros. Eścala $1 / 8$ 


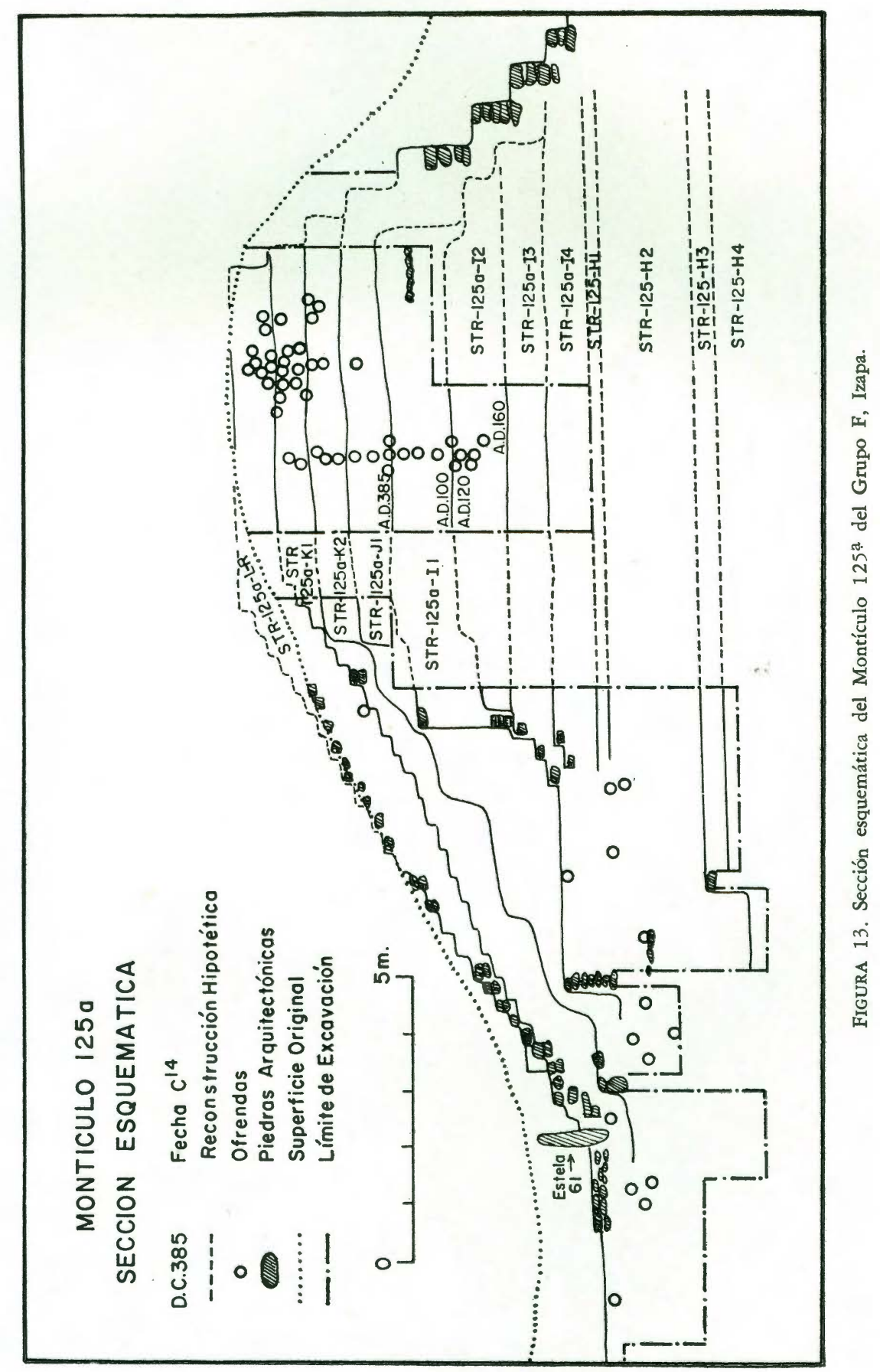

